\title{
Pathological Response and Sphincter preservation after Neoadjuvant Oral UFT and Pelvic Irradiation for Operable Rectal Cancer
}

\author{
Helmy S., Abo-Zeid A.A. ${ }^{1}$, Gado N.M., Salman M.I. ${ }^{2}$, El.Bassiouny M.M. and Abd Al Samee A. \\ Department of Clinical Oncology and Nuclear Medicine, Faculty of Medicine, Ain Shams University. \\ ${ }^{1}$ Department of Surgery, Faculty of Medicine, ${ }^{2}$ Department of Pathology, Faculty of Medicine, Ain \\ Shams University.
}

\begin{abstract}
Background: Preoperative radiotherapy is one of the standard treatment modalities for rectal cancer and is often combined with 5-fluorouracil-based chemotherapy. UFT (Uracil plus Tegafur), an oral 5FU derivative, given daily during a course of radiotherapy mimics the effect of continuous- infusion 5FU.

Aim of the work: To assess tolerance and efficacy of preoperative treatment with UFT and radiotherapy (RT) followed by surgery and postoperative fluorouracil (FU)/leucovorin (LV) in patients with locally advanced operable rectal cancer. End points included down staging, pathologic complete response, and sphincter preserving surgery.

Patients and Methods: Twenty- five patients with potentially resectable low to mid rectal tumors, aged 21-75 years, males/females: 16/9, clinical stages T3 $(n=20)$, T4 $(n=5)$ were treated with UFT $\left(400 \mathrm{mg} / \mathrm{m}^{2} / \mathrm{d}, 5\right.$ days a week for 6 weeks) and concomitant RT to the pelvis ( $45 \mathrm{~Gy} ; 1.8 \mathrm{~Gy} / \mathrm{d}$ over 5 weeks plus 5.4 Gy boost). Patients underwent surgery 5 to 6 weeks later followed by four cycles of FU/LV.

Results: All patients received the neoadjuvant chemoradiotherapy treatment. Three patients $(12 \%)$ received less than full dose of UFT. Preoperative G3+ toxicities included diarrhea (8\%), urinary tract infection (UTI) $(16 \%)$, and wet desquamation (24\%). Surgery done in 22 patients consisted of low anterior resection in 11 patients, abdominoperineal resection in 10 patients and proctectomy in 1 patient, the remaining three patients one progressed, one refused surgery while the third died. The down staging rate was (13/22 patients) $59.1 \%$, pathologic complete response (pCR) was $9.1 \%$ (2/22 patients) and the sphincter preservation rate was $13 \%$ (3/22 patients).

Conclusion: UFT combined with RT is well-tolerated and effective as neoadjuvant treatment of resctable rectal cancer as regarding down staging and sphincter preservation. Follow up is recommended to assess impact of this treatment on recurrence and survival.
\end{abstract}

Key words: Rectal cancer, UFT, sphincter preservation Corresponding Author: Mohamed elbassiouny

E-mail: dr.melbassiouny@gmail.com

\section{INTRODUCTION}

Colorectal cancer is the third most commonly diagnosed cancer in males and the second in females, with over 1.2 million new cancer cases and 608,700 deaths estimated to have occurred in $2008^{1}$. High incidence rates are found in North America, Western Europe, and Australia (approximately 40 to 45 cases per 100,000 population), and intermediate rates in Eastern Europe (approximately 26 per 100,000), with the lowest rates found in Africa (approximately 3 to 8 per 100,000) . $^{2}$ The male-to-female incidence rate ratio (IRR) is another characteristic of CRC patterns. In developed countries, the male to- female IRR tends to about 1.5 , and in less developed countries it is about $1.3^{3}$.

In Egypt rectal cancer age- standardized incidence rates and incidence rate ratios 1993-1997 were 2.3 and
2 per 100,000 population respectively in males and 1.8 and 1.8 per 100,000 population respectively in females ${ }^{4}$.

Radiotherapy and surgical resection are standard components of therapy for patients with stage II/III carcinoma of the rectum. Numerous randomized trials have investigated the impact of dose modifications and preoperative/postoperative administration in an effort to improve safety without compromising effectiveness, reduce the incidence of local recurrence, and significantly prolong survival ${ }^{5}$.

The Dutch Colorectal Cancer Group administered 25 Gy during 5 days followed by immediate total mesorectal resection and significantly reduced loco regional tumor recurrence at 2 years from $8.2 \%$ in the surgery-only arm 
to $2.4 \%$. The addition of radiotherapy did not prolong survival compared with surgery alone ${ }^{6}$.

The European Organization for Research and Treatment of Cancer (EORTC) evaluated the value of preoperative chemo-radiotherapy or preoperative radiotherapy alone and postoperative chemotherapy versus preoperative radiotherapy and surgery alone. The addition of fluorouracil and leucovorin to the preoperative administration of 45 Gy during 5 weeks reduced the loco regional recurrence from $17.1 \%$ to $8.5 \%$; the 5 -year overall survival (OS) did not improve with the addition of chemotherapy ${ }^{7}$.

The German Rectal Cancer Study Group trial compared preoperative to postoperative chemo radiotherapy in patients with clinical stage $\mathrm{T} 3$ or $\mathrm{T} 4$ or node-positive disease. The 5-year loco regional recurrence rate decreased from $13 \%$ in the postoperative group to $6 \%$. Survival was not different between the two groups ${ }^{8}$.

Advantages of neo-adjuvant chemo radiotherapy for locally advanced carcinoma of the middle and the lower third of the rectum are down staging and downsizing of the tumor ${ }^{9}$. Preoperative therapy can increase the rate of preserving surgery by shrinking the tumor and enhancing its distance from the anal sphincter ${ }^{10}$.

Theoretic common advantages of long- and shortcourse of preoperative RT include the better tumor radio sensitivity, coming from improved oxygenation of presurgical field, the reduction in tumor seeding by surgical handling and perhaps the reduced toxicity, due to the lesser amount of radiated small bowel ${ }^{11}$.

Although it had a positive effect when combined with preoperative radiation yet there is still a need to identify the optimal chemotherapy dose, optimal chemotherapeutic combination of drugs and the best administration schedule for 5FlouroUracil $(5 \mathrm{FU})^{7,8}$.

For practical reasons, early trials of 5-FU centered on bolus administration. However, preclinical evidence suggested that increased duration of exposure could improve efficacy. Because the plasma half-life of 5-FU is short ( 8 to 20 minutes), infusion administration schedules were developed in an attempt to increase efficacy. A meta-analysis involving 1,219 patients in six trials comparing protracted venous infusion (PVI) 5-FU with bolus reported an improved response rate of $22 \%$ versus $14 \%(P=.0002)$ in favor of PVI. Survival with PVI 5-FU was statistically superior, but this survival advantage was less than 1 month $^{12}$.

In postoperative treatment, the data of the Intergroup-0114 study did not demonstrate any advantage in the regimens that combined LV or levamisol with FU and RT over the scheme of bolus FU with $\mathrm{RT}^{13}$.

To overcome the 5-fluorouracil infusion-related problems, oral 5-fluorouracil precursors and inhibitors of 5-fluorouracil degradation have been developed and explored. These include oral fluoropyrimidines such as tegafur (ftorafur), uracil plus tegafur (UFT), S-1, eniluracil and the oral carbamate capecitabine ${ }^{14}$.

UFT is an oral formulation of the prodrug tegafur and uracil. Tegafur is converted to 5-FU primarily in the liver and uracil inhibits the degradation of 5-FU. The use of UFT is convenient without the necessity of a central venous catheter and the plasma concentrations of 5-FU on UFT treatment given in a $5 / 7$ days schedule mimics that of continuous venous infusion (CVI $)^{15}$.

Based on these observations this current phase II prospective single arm single institution trial was designed to test the efficacy and toxicity of UFT with radiotherapy in the preoperative setting in patients presented to our hospitals with potentially resectable low to mid rectal tumors can tolerate chemo-radiotherapy during study period, with complete pathological response, down staging and sphincter preservation as end points.

\section{Patients and methods:}

This prospective phase II study included 25 patients with potentially resectable, locally advanced cancer rectum proved clinically, pathologically and radiologically who presented to Clinical Oncology and Nuclear medicine Department and General Surgery Department, Ain Shams University Hospitals. This study took place during the period from April 2008 to January 2011 inclusive; last patient was enrolled in june 2010.

\section{Eligibility criteria:}

Patients' age lied between 18-75 years old. Patients had to be diagnosed of an adenocarcinoma of the middle or lower rectum to a distance of $2-12 \mathrm{~cm}$ from the anal verge by rigid rectoscopic evaluation and biopsy for histopathological diagnosis. Clinical and radiological evaluation had to prove cT3 or cT4 or any cT with $\mathrm{N}+$ stage. All patients needed to have an Eastern Cooperative Oncology Group performance status equal or less than $2^{16}$, adequate bone marrow reserve $(\mathrm{WBC}>4,000, \mathrm{Hb}$ $>10$, and platelets $>150,000)$ and adequate renal and hepatic functions: total bilirubin $\leq 1.25 \times$ upper normal limits, creatinine $\leq 1.25 \times$ upper normal limit, AST and ALT $\leq 2.5 \times$ upper normal limits. All patients had to be chemotherapy and radiotherapy naïve. Exclusion criteria were distant metastasis, history of previous cancer, and pregnant females. Patients had to be free of unresolved bowel obstruction or sub obstruction, and free of any serious illness or medical conditions. 


Vol. 8 | No. 3-4 $2012 \quad$ Helmy S. et al.

\section{Pretreatment evaluation:}

The pretreatment examination included history and clinical examination, digital rectal examination (DRE), a complete colonoscopy, chest $\mathrm{x}$-ray, pelvi-abdominal computed tomography (CT), endo-rectal US or pelviabdominal MRI if there was rectal stricture or severely painful anal condition that made endo-rectral US not possible. Laboratory evaluations included CBC, LFT, KFT, and baseline carcinoembryonic antigen level (CEA). Other radiological investigations to exclude distant metastases were done when clinically indicated i.e bone scan if bony tenderness and MRI brain if suspected brain metastases.

\section{Preoperative treatment:}

Treatment was administered on an outpatient basis for six weeks. Patients received therapy in form of preoperative concomitant chemo radiotherapy followed by surgery.

\section{Chemotherapy:}

Patients received UFT of $400 \mathrm{mg} / \mathrm{m}^{2} /$ day in three divided doses between meals during the days of radiotherapy (Sunday to Thursday, with Friday and Saturday as rest period). Complete blood picture and biochemical profile were requested every week.

\section{Radiotherapy:}

Concomitant radiotherapy to the pelvis (45 GY; $1.8 \mathrm{GY} / \mathrm{d}$, five days per week with weekend on Friday and Saturday as a rest period, over 5 weeks). The dose was boosted by adding $(5.4 \mathrm{GY} ; 1.8 \mathrm{GY} / \mathrm{d})$ after pelvic irradiation. Irradiation was delivered with linear accelerator photon beam machine of $\geq 6 \mathrm{MV}$. All patients were simulated in prone position with fields oriented as one posterior and two laterals. The upper border was set at L5-S1, and the lower border was set $3 \mathrm{~cm}$ distal to lower border of the tumor. Laterally the field extended $2 \mathrm{~cm}$ beyond the bony pelvis at its widest point. The anterior border of the lateral field was set at the posterior border of symphysis pubis in T3 lesions and at the anterior border of symphysis pubis in T4 lesions. The posterior border of the lateral field was set $1 \mathrm{~cm}$ behind sacrum. CT-contour was done at the centre of the three fields for dose distribution. The boost field was designed with 3 $\mathrm{cm}$ margin around the primary lesion, by two parallel opposing AP-PA fields.

\section{Postneoadjuvant and preoperative evaluation:}

Clinical response was assessed 4-5 weeks after finishing neo-adjuvant chemo-radiotherapy using the same diagnostic investigations done prior to treatment.

\section{Surgery:}

Patients were scheduled for surgery between the fifth and sixth week following the end of the combination therapy and were treated with total mesorectal excision with free resection margin $\geq 1 \mathrm{~cm}$.

\section{Postoperative chemotherapy:}

Postoperative chemotherapy for 4 courses of Mayo Clinic protocol; intravenous infusion over 1- 2 hours each (5FU $425 \mathrm{mg} / \mathrm{m}^{2}$ and LV $20 \mathrm{mg} / \mathrm{m}^{2}$ on days $\left.1-5\right)$ was scheduled every 4 weeks for all cases.

\section{Follow up:}

Following the end of treatment, patients had outpatient clinic appointments every 3 months for the first 2 years. Per rectal (PR) examination, $\mathrm{CBC}$, and CEA were performed every 3 months, CXR, and abdomenpelvis CT every year, proctoscopy was done every 6 months for those patients after LAR and colonoscopy was done in one year except if not done preoperatively due to obstructing lesion, in this case it was done in 3-6 months.

\section{Toxicity assessment and dose attenuation:}

Toxicity of the concurrent chemo radiotherapy treatment was evaluated weakly in each patient according to CTC Version $2.0^{17}$ and RTOG/EORTC toxicity criteria ${ }^{18}$ for chemotherapy and radiotherapy respectively. A CBC was obtained weekly. UFT was suspended if diarrhea grade 3 or worse occurred and started over again with a dose reduction of $50 \mathrm{mg} / \mathrm{m}^{2}$ when the diarrhea grade was no greater than 1 . Radiotherapy was suspended if there was diarrhea grade 3 or wet desquamation of the skin occurred and recommended when diarrhea was 1 or less and desquamation healed.

\section{Definition of response:}

Analysis of the response to preoperative treatment was defined clinically as well as pathologically. Down staging was considered when pathological $\mathrm{T}(\mathrm{pT})$ was less than ultrasound T (uT) by endorectal US or clinical $\mathrm{T}(\mathrm{cT})$ by CT or MRI. No response was considered when pT and $\mathrm{uT}$ or cT was similar. Disease progression was considered when $\mathrm{pT}$ was $>\mathrm{uT}$ or $\mathrm{cT}$ or when metastases was observed during surgery. Resected tumors were classified pathologically according to the tumor-nodemetastasis system $(\mathrm{TNM})^{19}$.

\section{Data management and analysis:}

The collected data was revised, coded, tabulated and introduced to a PC using Statistical package for Social Science (SPSS 15.0.1 for windows; SPSS Inc, Chicago, IL, 2001). Chi-Square test was used to examine the relationship between two qualitative variables

\section{RESULTS}

Patients, clinic-pathological criteria are shown in Table (1). 


\section{Toxicity and treatment adherence:}

\section{Preoperative treatment:}

During preoperative treatment $88 \%$ of patients $(22$ patients) received full course of UFT while $12 \%$ of patients (3 patients) received UFT below full dose; due to diarrhea grade 3- 4 that needed dose reduction. Chemo radiotherapy was received without any delay in $72 \%$ of patients (18 patients) and with delay $1-2$ weeks in $28 \%$ of patients (7 patients); one due to diarrhea grade 4 and six due to wet desquamation of the skin. The toxicity observed in the 25 patients during the preoperative part of treatment was mainly gastrointestinal, skin desquamation, and to some extent urinary complications (Table 2). Patients with grade 3 and 4 diarrhea were $12 \%$ (3 patients). All of the patients were controlled with antidiarrheal medications and intestinal antiseptics. Radiotherapy delay 1 week because of diarrhea occurred in only 1 patient (1/25). Hand and foot syndrome was not noticed in any of the studied group of patients during neo-adjuvant treatment period.

\section{Surgery:}

Of the 25 patients that completed the preoperative treatment, 22 patients were operated on: one patient died of hepatorenal insufficiency unrelated to treatment which developed at the 8 th week after preoperative treatment, and before the scheduled surgery. Another one patient with lower rectal mass with no possibility of sphincter preservation refused to do abdominoperineal resection with permanent colostomy and developed pulmonary metastases 4 months later without further chemotherapy. In one patient, tumor progression and development of peritoneal nodules made it irresectable.

Of the 22 patients, 14 had the tumor in the distal third of the rectum $(2-6 \mathrm{~cm})$ and 8 had the tumor in middle third (7-12). Of the 22 patients who had the primary tumor resected, $45.5 \%$ of patients (10 patients) had abdominoperineal (APR), 50\% of patients (11 patients) had low anterior resection (LAR) and $4.5 \%$ of patients (1 patient) had proctectomy via abdominoperineal resection. The surgery was considered radical in $90.9 \%$ of patients (20 patients) and it was considered palliative in $9.1 \%$ of patients ( 2 patients) because in one patient there was heavy lymphatic infiltration up to inferior mesenteric lymph nodes which could not be resected and in another patient there was severe perirectal fibrosis and adhesions to sacrum and pelvic side walls which enabled only proctectomy without total mesorectal excision. One patient 70 years old died immediately postoperatively as a result of cerebrovascular stroke. Delay in wound healing occurred in $23.8 \%$ of patients (5 patients). Pelvic abscess developed in $4.5 \%$ of patients (1 patient), Table (3).

\section{Postoperative treatment:}

Of the 22 patients having surgery and who were candidate for adjuvant chemotherapy two patient $(9 \%)$ did not receive chemotherapy; one because he developed acute intestinal obstruction and died before adjuvant chemotherapy and the other one who died immediately postoperatively of cerebrovascular stroke. Of the 20 patients who received adjuvant chemotherapy, two patients received chemotherapy after delay of 4-5 months as they took long time to recover from surgery, one of them developed burst abdomen and took 5 months to heal with healthy granulation tissue.

Efficacy: Down staging, Pathologic complete response and Sphincter preservation

Following the preoperative treatment, the pathological staging of the 22 patients operated upon according to TNM staging system is shown in Table (4) and Figure (1).

In view of previously shown data PCR rate of $9.1 \%$ $(2 / 22)$ was encountered. By comparing clinical $T$ stage and pathological $\mathrm{T}$ stage down staging was found to be $59.1 \%(13 / 22)$ and no disease progression was observed in any of the operated patients, pathological staging results are shown in Table (5).

The relationship between down staging and clinicopathological characteristics was analysed and the results showed that there is no significant relationship between downstaging and age, performance status, CEA level, clinical $\mathrm{T}$ stage, clinical $\mathrm{N}$ stage, distance of the tumor from anal verge and distance of low rectal tumors from the anal verge but downstaging was more obvious in males than in females with high statistically significance $(P=0.003)$, in adenocarcinoma than in mucoid carcinoma with statistical significance $(P=0.047)$, and in moderately differentiated carcinoma than in poorly differentiated carcinoma with statistical significance $(P=0.01)$.

In 14 patients of operated patients, the tumor was found in the distal $1 / 3$ of the rectum, 5 patients had the tumor $<2 \mathrm{~cm}$ from the anal verge or that had infiltrated the sphincter muscles and those patients were candidate for APR from the start, the other 9 patients had a tumor distance of $\geq 2 \mathrm{~cm}$ from the anal verge. In these cases, the surgeon, in clinical evaluation before presurgical treatment, decided these patients should undergo APR and in $13.6 \%$ of them $(3 / 22)$, it was possible to preserve the sphincter.

The relationship between sphincter preservation and clinicopathological characteristics was analyzed and no significant relationship was found between sphincter preservation and sex, age, performance status, CEA level, pathological grade, clinical $\mathrm{T}$ stage and clinical $\mathrm{N}$ stage but sphincter preservation was more obvious in adenocarcinoma than mucoid type with statistically significant relationship $(P=0.018)$. 


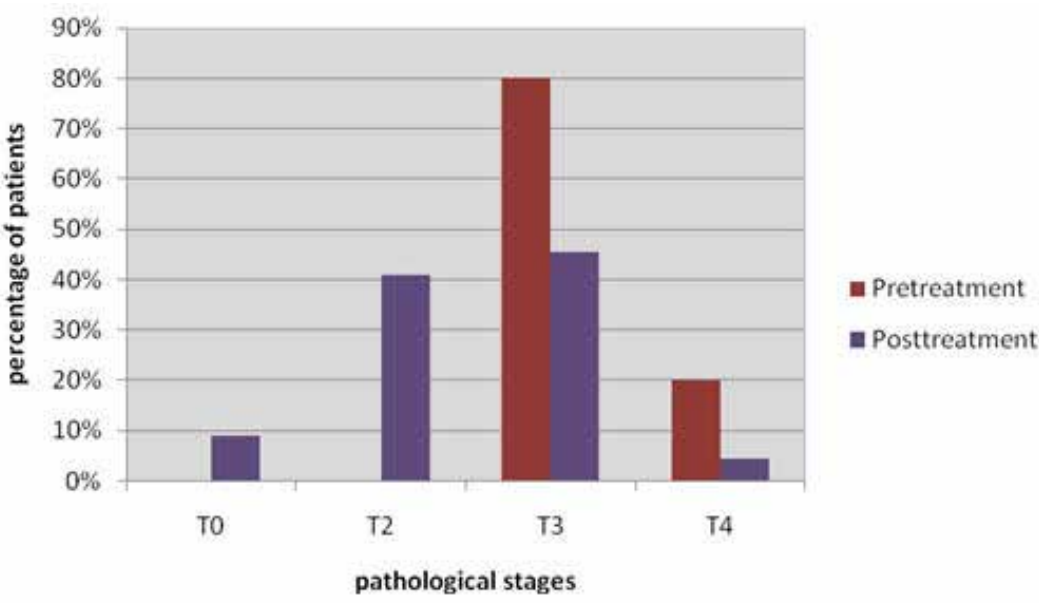

Figure 1: description of cases according to $\mathrm{T}$ staging before and after chemoradiotherapy treatment.

Table 1: Clinicopathologic characteristics of study patients $(n=25)$

\begin{tabular}{|c|c|c|c|}
\hline Clinicopathologic patients characteristics & & Number (25) & Percentages $(100 \%)$ \\
\hline \multirow[t]{2}{*}{ Sex } & Male & 16 & 64.0 \\
\hline & Female & 9 & 36.0 \\
\hline \multirow{3}{*}{ Age } & Mean \pm SD & \multicolumn{2}{|c|}{$47.5 \pm 15.7$} \\
\hline & Median & \multicolumn{2}{|c|}{46} \\
\hline & Range & \multicolumn{2}{|c|}{$21-75$} \\
\hline \multirow[t]{2}{*}{ Performance status } & Zero & 14 & 56.0 \\
\hline & One & 11 & 44.0 \\
\hline \multirow[t]{2}{*}{ CEA } & Normal & 20 & 80.0 \\
\hline & High & 5 & 20.0 \\
\hline \multirow[t]{2}{*}{ Pathologic type } & Adenocarcinoma & 17 & 68.0 \\
\hline & Mucoid & 8 & 32.0 \\
\hline \multirow[t]{2}{*}{ Grade } & Moderately differentiated & 19 & 86.4 \\
\hline & Poorly differentiated & 3 & 13.6 \\
\hline \multirow[t]{2}{*}{ Dist of rectal tumor from anal verge } & Mid-Rectal (7-12cm) & 9 & 36.0 \\
\hline & Low-Rectal (2-6cm) & 16 & 64.0 \\
\hline \multirow{2}{*}{ Dist of low rectal tumor from anal verge } & $\leq 2 \mathrm{~cm}$ & $6 / 16$ & 37.5 \\
\hline & $>2 \mathrm{~cm}$ & $10 / 16$ & 62.5 \\
\hline \multirow[t]{4}{*}{ Clinical stage (cTN) } & T3 N0 & 9 & 36.0 \\
\hline & $\mathrm{T} 3 \mathrm{~N}+$ & 11 & 44.0 \\
\hline & T4 N0 & 1 & 4.0 \\
\hline & $\mathrm{T} 4 \mathrm{~N}+$ & 4 & 16.0 \\
\hline \multirow[t]{2}{*}{$\mathrm{cT}$} & $\mathrm{T} 3$ & 20 & 80.0 \\
\hline & $\mathrm{T} 4$ & 5 & 20.0 \\
\hline \multirow[t]{2}{*}{$\mathrm{cN}$} & No & 10 & 40.0 \\
\hline & $\mathrm{N}+$ & 15 & 60.0 \\
\hline
\end{tabular}


Kasr-El-Aini Journal Of Clinical Oncology And Nuclear Medicine

Vol. 8 | No. 3-4 2012

Pathological Response and Sphincter preservation

Table 2: Description of neoadjuvant treatment related complication among study patients.

\begin{tabular}{|c|c|c|c|c|c|c|c|c|c|c|}
\hline \multirow[t]{2}{*}{ Toxicity } & \multicolumn{2}{|l|}{ Grade 1} & \multicolumn{2}{|l|}{ Grade 2} & \multicolumn{2}{|l|}{ Grade 3} & \multicolumn{2}{|l|}{ Grade 4} & \multicolumn{2}{|l|}{ G 3-4 } \\
\hline & No of patients & $\%$ & No of patients & $\%$ & No of patients & $\%$ & No of patients & $\%$ & No of patients & $\%$ \\
\hline Anemia & - & - & 2 & 8 & - & & - & - & - & - \\
\hline Leucopenia & - & - & 1 & 4 & - & & - & - & - & - \\
\hline Diarrhea & - & - & 6 & 24 & 2 & 8 & 1 & 4 & 3 & 12 \\
\hline UTI & - & - & - & - & 4 & 16 & - & - & 4 & 16 \\
\hline Radiation dermatitis & - & - & - & - & - & - & 6 & 24 & 6 & 24 \\
\hline
\end{tabular}

Table3: Description of surgical treatment and its related complication among study patients (22 patients).

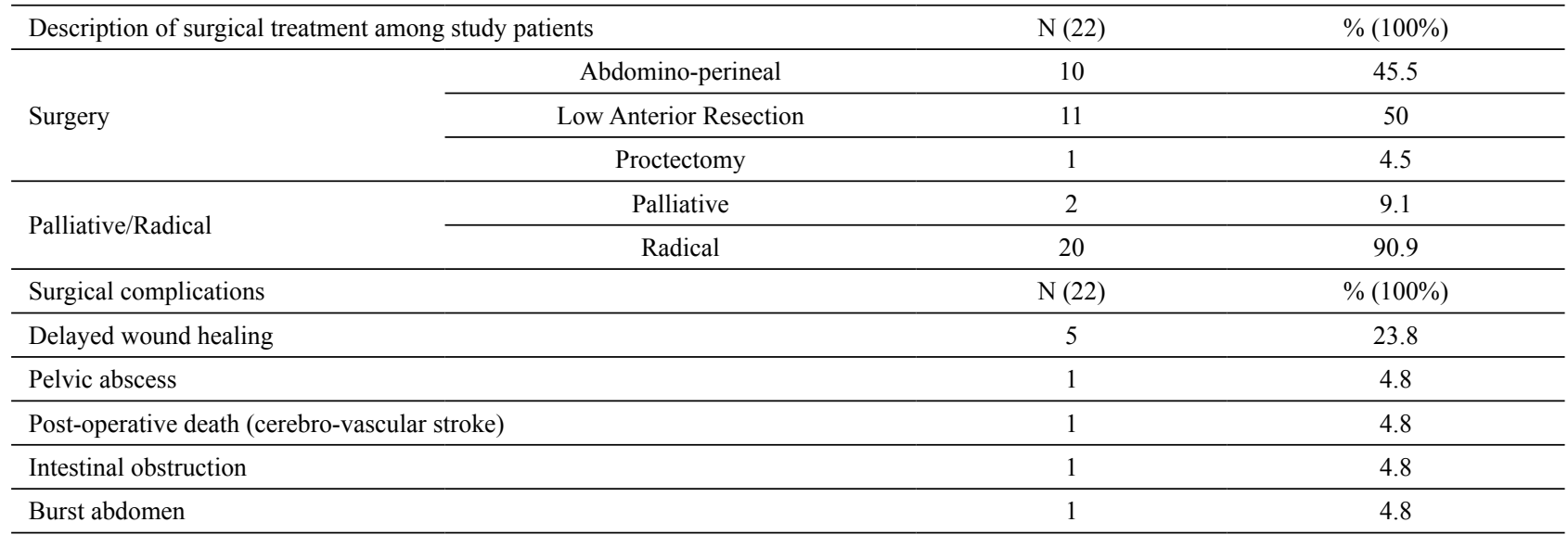

Table4: Description of postoperative data of study patients.

\begin{tabular}{|c|c|c|c|}
\hline \multicolumn{2}{|c|}{ Description of postoperative data of study patients } & $\mathrm{N}(22)$ & $\%(100 \%)$ \\
\hline \multirow{8}{*}{ Pathological stage (pTN) } & pT0 N1 & 1 & 4.5 \\
\hline & pT0 N2 & 1 & 4.5 \\
\hline & pT2 N0 & 6 & 27.3 \\
\hline & pT2 N1 & 3 & 13.6 \\
\hline & pT3 N0 & 2 & 9.1 \\
\hline & pT3 N1 & 1 & 4.5 \\
\hline & pT3 N2 & 7 & 31.8 \\
\hline & pT4 N2 & 1 & 4.5 \\
\hline \multirow{4}{*}{$\mathrm{pT}$} & pT0 & 2 & 9.1 \\
\hline & pT2 & 9 & 40.9 \\
\hline & pT3 & 10 & 45.5 \\
\hline & pT4 & 1 & 4.5 \\
\hline \multirow{3}{*}{$\mathrm{pN}$} & pN1 & 5 & 22.7 \\
\hline & $\mathrm{pN} 2$ & 9 & 40.9 \\
\hline & $\mathrm{pN} 0$ & 8 & 36.4 \\
\hline Complete response & & 2 & 9.1 \\
\hline Down staging & & 13 & 59.1 \\
\hline Stationary disease & & 7 & 31.8 \\
\hline Sphincter preservation & & 3 & 13.6 \\
\hline
\end{tabular}

Table 5: Down staging: Clinical T stage Versus Pathologic T stage.

\begin{tabular}{lccccccc}
\hline cT (before treatment) & pCR & P T1 & P T2 & P T3 & P T4 & \multicolumn{2}{c}{$\begin{array}{c}\text { Downstaging } \\
\text { No }\end{array}$} \\
\hline c T3 $(\mathrm{n}=19)$ & 2 & 0 & 9 & 8 & 0 & $11 / 19$ & 57.9 \\
c T4 $(\mathrm{n}=3)$ & 0 & 0 & 0 & 2 & 1 & $2 / 3$ & 66 \\
\hline Total $(\mathrm{n}=22)$ & 2 & 0 & 9 & 10 & 1 & $13 / 22$ & 59.1 \\
\hline
\end{tabular}




Vol. 8 | No. 3-4 $2012 \quad$ Helmy S. et al.

\section{DISCUSSION}

Several trials on perioperative therapy in rectal cancer have significantly contributed to a better understanding of an optimized therapeutic strategy during the past few years. It could be demonstrated that (i) one of the best ways to deliver radiotherapy as neoadjuvant (CAO/AIOARO-94 trial ${ }^{8}$; MRC CR07 $-^{20}$ ), (ii) adding 5-FU to neoadjuvant radiotherapy improves the $\mathrm{pCR}$ and the local recurrence rates at the expense of higher acute toxicity (EORTC $22921-^{21}$; FFCD $9203-{ }^{22}$ ), (iii) postoperative 5-FU based adjuvant therapy might further improve disease-free survival (EORTC $22921-^{21}$ ).

In postoperative treatment, the data of the Intergroup-0114 study did not demonstrate any advantage in the regimens that combined LV or levamisol with FU and RT over the scheme of bolus FU with $\mathrm{RT}^{13}$.

In phase I studies, in advanced disease, the recommended dose of UFT without $\mathrm{LV}$ is $360 \mathrm{mg} / \mathrm{m}^{2}$ over 28 of 35 days $^{23}$. In the study by Hoff and his colleagues ${ }^{24}$, the recommended dose for the combination of RT and UFT/LV was similar to that used in advanced disease.

Because the standard schedule of preoperative radio chemotherapy for rectal cancer remains to be established, and due to the convenience of oral prodrugs of 5-FU, we evaluated the activity of UFT without LV and preoperative radiotherapy in patients with stage II-III rectal cancer based on observations from postoperative studies on 5FU/LV and phase I studies on UFT and LV. Hence, we used a scheme of dose of UFT of $400 \mathrm{mg} / \mathrm{m}^{2} / 5$ days per week during the days on which the RT was administered.

Results of the current study showed that preoperative treatment achieved tumor down staging in 59.1\% of patients. The pathological complete response rate (pT0) was achieved in $9.1 \%$ of patients, and the percentage of sphincter-preserving procedures was $13.6 \%$.

Similar results have been reported in previous studies on preoperative chemo radiation with UFT; Feliu and his colleges ${ }^{25}$ reported Down staging (61\%) and pCR (15\%), Gamelin and co-workers ${ }^{26}$ reported down staging of (48\%) and pCR of (25\%); this higher pCR may be attributed to better patients, stage (uT3: N0 11, N1 18) at presentation than ours, Kundel and his colleagues $^{27}$ reported down staging of (42\%), and pCR of $(10 \%)$ and Qvortrup and co-workers ${ }^{28}$ reported pCR $(10 \%)$.

In comparison to 5FU/LV combined with radiotherapy studies; Seok and co-workers ${ }^{29}$ reported down staging (52.6\%) and pCR (5.3\%). Similarly Sauer and his colleagues ${ }^{8}$ reported pCR (8\%) and NSABP R-03, 2009 study $^{30}$ reported pCR (19\%), also Gérard and his colleagues ${ }^{31}$ reported pCR $(11.4 \%)$ in his chemo radiotherapy arm.

Comparing our study to capecitabine combined with radiotherapy studies; De Paoli and his colleagues ${ }^{32}$ reported down staging of $(57 \%)$ and pCR of $(24 \%)$. Vaneja and co-workers ${ }^{33}$ reported down staging (40\%) and pCR (9.1\%).

The reported rates of sphincter preservation in phase II trials were more or less variable. In UFT based preoperative trials Wang and co-workers ${ }^{34}$ reported sphincter preservation rate $(55 \%)$. Fernandez-Martos and his colleagues ${ }^{35}$ reported sphincter preservation rate (25\%). Kundel and his colleagues ${ }^{27}$ in his study reported much higher sphincter preservation rate of $(71 \%)$. Compared to other studies on preoperative 5FU with radiotherapy; Seok and co-workers ${ }^{29}$ reported sphincter preservation rate $(60 \%)$ and Sauer and his colleagues ${ }^{8}$ reported sphincter preserving surgery rate of (39\%).

Nevertheless studies on capecitabine with radiotherapy preoperatively; De Paoli and co-workers, $2006^{32}$ reported sphincter preservation rate (59\%) and Vaneja and his colleagues ${ }^{33}$ reported sphincter preservation rate $(37 \%)$. Jae-Sung and his colleagues ${ }^{36}$ reported sphincter preservation $(66.7 \%)$ in capecitabine containing arm.

One of the major concerns about neoadjuvant treatment is that toxicity might counterbalance the theoretical advantages. In our series, $12 \%$ of patients suffered grade 3-4 diarrhea. As regarding hematologic toxicity, there was only one patient with leucopenia G2 (4\%), and two patients with anemia G2 $(8 \%)$. As regarding skin complications, radiation dermatitis G4 (wet desquamation) was encountered in our study in $24 \%$ of cases.

In other studies the toxicity most frequently encountered was also diarrhea G3-4. Compared to 5FU containing regimens, diarrhea G3-4 was (36\%) in the preoperative arm of NSABP R-03 study ${ }^{30}$ Compared to UFT containing regimens, Fernandez-Martos and his colleagues $^{35}$ reported diarrhea G3-4 (14\%), Wang and co-workers ${ }^{34}$ reported diarrhea G3-4 of (9\%). Compared to capecitabine containing regimens, G3-4 diarrhea was $(11.3 \%)$ in capecitabine arm of phase III study reported by Jae-Sung and co-workers ${ }^{36}$.

Hand and foot syndrome was not seen in this study or any study containing UFT or 5FU regimens compared to capecitabine containing regimens, Jae-Sung and his colleagues $^{36}$ reported hand and foot syndrome G3-4 $(6.2 \%)$ in capecitabine arm, De Paoli and co-workers ${ }^{32}$ 
reported hand and foot syndrome G1-2 in (9\%) and G3 in $(4 \%)$, Vaneja and his colleagues ${ }^{33}$ reported hand and foot syndrome G1 (28\%) and in G3 (7\%).

In conclusion, there is considerable interest for oral fluoropyrimidines in the neo-adjuvant treatment of rectal cancer. UFT with radiotherapy in the neoadjuvant treatment of locally advanced adenocarcinoma of middle-lower rectum relative to therapy with standard 5FU or with capecitabine, seems to be active, safe and has a favorable risks/benefits relationship that makes it an acceptable option in the neo-adjuvant treatment of locally advanced middle-lower rectal adenocarcinoma. Also it exhibits a preferable toxicity profile as evidenced by diminished diarrhea G3-4 toxicity compared to 5FU containing regimens and no hand foot syndrome compared to capecitabine containing regimens. Analysis of follow up data of included patients in the study is recommended to assess impact of this treatment on recurrence and survival.

\section{REFERENCES}

1. Jemal A, Bray F, Center MM, Ferlay J, Ward E, Forman D. Global cancer statistics. CA Cancer J.Clin. 2011; 61(2):69-90.

2. Rödel C, Valentini V, Minsky B. Rectal Cancer. In: Gunderson LL, Tepper JE, editors. Clinical Radiation Oncology. 2nd ed. USA: Philadelphia, PA; 2007. pp. 1113-43.

3. Ferlay J, Bray F, Pisani P and Parkin DM. GLOBOCAN 2002: Cancer incidence, mortality and prevalence worldwide. IARC Cancer Base No. 5. version 2.0. Lyon (France). 2004. IARC Press.

4. Parkin DM, Whelan SL, Ferlay J, Teppo L and Thomas DB. Cancer Incidence in Five Continents Volume VIII. 2002. IARC scientific publication No 155.

5. Colorectal Cancer Collaborative Group. Adjuvant therapy for rectal cancer: A systematic overview of 8507 patients from 22 randomised trials. Lancet 2001;358(1291):1304

6. Kapiteijn E, Marijnen CAM, Nagtegaal ID. Preoperative radiotherapy in combination with total mesorectal excision improves local control in resectable rectal cancer. Report from a multicenter randomized trial. For the Dutch Colo Rectal Cancer Group and other cooperative investigators. N.Engl.J.Med. 2001;345:638-646.

7. Bosset JF, Collette L, Calais G, Mineur L, Maingon P, Radosevic-Jelic L, et al. Chemotherapy with preoperative radiotherapy in rectal cancer. N.Engl.J.Med. 2006;355(11):1114-23.

8. Sauer R, Becker H, Hohenberger W, Rödel C, Wittekind $\mathrm{C}$, Fietkau R, et al. Preoperative versus postoperative chemoradiotherapy for rectal cancer. N.Engl.J.Med. 2004;351(17):1731-40.
9. Jonas J, Moroni E, Cavallaro A, Colasanti M, SautterBihl ML, Frenzel H, et al. T-level downstaging and complete pathologic response after preoperative long-term radiochemotherapy for locally advanced rectal cancer. $\mathrm{G}$ Chir. 2007;28(3):65-71.

10. Gavioli M, Losi L, Luppi G, Iacchetta F, Zironi S, Bertolini F, et al. Preoperative therapy for lower rectal cancer and modifications in distance from anal sphincter. Int.J.Radiat.Oncol.Biol.Phys. 2007;69(2):370-5.

11. Biffi R, Marsiglia H, Fossa BJ, Leonardi MC, Cante D, Lazzari R, et al. Preoperative bi-fractionated accelerated radiation therapy for combined treatment of locally advanced rectal cancer in a consectutive series of unselected patients. Int.Semin.Surg.Oncol. 2007;4:23.

12. Efficacy of intravenous continuous infusion of fluorouracil compared with bolus administration in advanced colorectal cancer. Meta-analysis Group In Cancer. J.Clin.Oncol. 1998;16(1):301-8.

13. Tepper JE, O'Connell M, Niedzwiecki D, Hollis DR, Benson AB3, Cummings B, et al. Adjuvant therapy in rectal cancer: Analysis of stage, sex and local control--final report of intergroup 0114. J.Clin.Oncol. 2002;20(7):1744-50.

14. Corvò R, Pastrone I, Scolaro $\mathrm{T}$, Marcenaro $\mathrm{M}$, Berretta L, Chiara S. Radiotherapy and oral capecitabine in the preoperative treatment of patients with rectal cancer: Rationale, preliminary results and perspectives. Tumori 2003;89(4):361-7.

15. Sadahiro S, Suzuki T, Kameya T, Iwase H, Tajima T, Makuuchi H. A pharmacological study of the weekdayon/weekend-off oral UFT schedule in colorectal cancer patients. Cancer Chemother.Pharmacol. 2001;47(5):457-60.

16. Oken MM, Creech RH, Tormey DC, Horton J, Davis TE, McFadden ET, et al. Toxicity and response criteria of the Eastern Cooperative Oncology Group. Am.J.Clin.Oncol. 1982;5(6):649-55.

17. Cancer Therapy Evaluation Program. Common Toxicity Criteria, Version 2.0. 1998. CTC.

18. Cox JD, Stetz J, Pajak TF. Toxicity criteria of the Radiation Therapy Oncology Group (RTOG) and the European Organization for Research and Treatment of Cancer (EORTC). Int.J.Radiat.Oncol.Biol.Phys. 1995;31(5):1341-6.

19. Greene FL, Page DL, Fleming ID, Fritz A, Balch CM, Haller DG, et al. AJCC Cancer Staging Manual. 6th ed. New York: Springer-Verlag; 2002.

20. Sebag-Montefi ore D, Steele R, Quirke P, et al. Routine short course. pre-op radiotherapy or selective postop chemoradiotherapy for resectable rectal cancer? Preliminary results of the MRC CR07 randomised trial. Proc.Am.Soc.Clin.Oncol. 2006;24:abstr 3511.

21. Bosset JF, Calais G, Mineur L, Maingon P, RadosevicJelic L, Daban A, et al. Preoperative radiation (Preop RT) in rectal cancer: Effect and timing of additional chemotherapy (CT) 5-year results of the EORTC 22921 trial. Proc.Am.Soc.Clin.Oncol. 2005;23(Suppl 16):3505. 


Vol. 8 | No. 3-4 $2012 \quad$ Helmy S. et al.

22. Gerard JP, Bonnetain F, Conroy T. Preoperative radiotherapy $\pm 5 \mathrm{FU} /$ folinic acid in T3-4 rectal cancers: Results of the FFCD 9203 randomized trial. Proc.Am.Soc. Clin.Oncol. 2005;23(16 Suppl):abstr 3504.

23. Pazdur R, Lassere Y, Diaz-Canton E, Bready B, Ho DH. Phase I trials of uracil-tegafur (UFT) using 5 and 28 day administration schedules: Demonstration of scheduledependent toxicities. Anticancer Drugs 1996;7(7):728-33.

24. Hoff PM, Janjan N, Saad ED, Skibber J, Crane C, Lassere $\mathrm{Y}$, et al. Phase I study of preoperative oral uracil and tegafur plus leucovorin and radiation therapy in rectal cancer. J.Clin.Oncol. 2000;18(20):3529-34.

25. Feliu J, Calvilio J, Escribano A, de Castro J, Sánchez ME, Mata A, et al. Neoadjuvant therapy of rectal carcinoma with UFTleucovorin plus radiotherapy. Ann.Oncol. 2002;13(5):730-6.

26. Gamelin E, Cellier P, Leduc B, Martin L, Jacob J, Vendrely $\mathrm{V}$, et al. Preoperative radiation and daily oral uft in combination with leucovorin (LV) in locally advanced rectal (LARC) cancer. J.Clin.Oncol. 2004;22(14 Suppl):3676.

27. Kundel Y, Brenner B, Symon Z, Oberman B, Sadezki S, Koller M, et al. A phase II study of oral UFT and leucovorin concurrently with pelvic irradiation as neoadjuvant chemoradiation for rectal cancer. Anticancer Res. 2007;27(4C):2877-80.

28. Qvortrup C, Jakobsen A, Hansen F, Baatrup G, Bisgaard C, Rasmussen P, et al. A phase II trial of highdose radiotherapy (60 Gy) and UFT/1-leucovorin in patients with locally advanced rectal cancer (LARC): Long-term results. J.Clin.Oncol. 2004;22(14 Suppl):3590.

29. Lee SH, Lee KC, Choi JH, Oh JH, Baek JH, Park SH, et al. Chemoradiotherapy followed by surgery in rectal cancer: Improved local control using a moderately high pelvic radiation dose. Jpn.J.Clin.Oncol. 2008;38(2):112-21.
30. Roh MS, Colangelo LH, O'Connell MJ, Yothers G, Deutsch M, Allegra CJ, et al. Preoperative multimodality therapy improves disease-free survival in patients with carcinoma of the rectum: NSABP R-03. J.Clin.Oncol. 2009;27(31):5124-30.

31. Gérard JP, Conroy T, Bonnetain F, Bouché O, Chapet O, Closon-Dejardin MT, et al. Preoperative radiotherapy with or without concurrent fluorouracil and leucovorin in T3-4 rectal cancers: Results of FFCD 9203. J.Clin.Oncol. 2006;24(28):4620-5.

32. De Paoli A, Chiara S, Luppi G, Friso ML, Beretta GD, Del Prete S, et al. Capecitabine in combination with preoperative radiation therapy in locally advanced, resectable, rectal cancer: A multicentric phase II study. Ann.Oncol. 2006;17:246-51.

33. Velenik V, Anderluh F, Oblak I, Strojan P, Zakotnik B. Capecitabine as a radiosensitizing agent in neoadjuvant treatment of locally advanced resectable rectal cancer: Prospective phase II trial. Croat.Med.J. 2006; 47(5):693-700

34. Wang LW, Yang SH, Lin JK, Lin TC, Chan WK, Chen WS, et al. Pre-operative chemoradiotherapy with oral tegafur-uracil and leucovorin for rectal cancer. J.Surg.Oncol. 2005;89(4):256-263; discussion 263-4.

35. Fernández-Martos C, Aparicio J, Bosch C, Torregrosa M, Campos JM, Garcera S, et al. Preoperative uracil, tegafur and concomitant radiotherapy in operable rectal cancer: A phase II multicenter study with 3 years' follow-Up. J.Clin. Oncol. 2004;22(15):3016-22.

36. Kim JS, Kim JS, Cho MJ, Yoon WH, Song KS. Comparison of the efficacy of oral capecitabine versus bolus 5-FU in preoperative radiotherapy of locally advanced rectal cancer. J.Korean Med.Sci. 2006;21(1):52-7. 